\title{
Emoções e Ensino Crítico de Línguas: uma abordagem político-cultural das emoções de uma professora de Inglês
}

\section{Emotions and Critical Language Teaching: A Political-Cultural Approach of an English Teacher's Emotions}

\author{
Ana Cláudia Turcato de Oliveira* \\ *Universidade Federal do Tocantins (UFT), Palmas, Tocantins / Brasil \\ anaturcato@uft.edu.br
}

https://orcid.org/0000-0001-8256-7964

\begin{abstract}
RESUMO: Há pouco tempo, o papel das emoções na vida docente, bem como seu impacto na sala de aula de línguas, foi amplamente negligenciado (BENESCH, 2012). Após o advento da "virada afetiva", o campo da Linguística Aplicada (LA) começou a contemplar estudos sobre emoções (BARCELOS, 2015; PAVLENKO, 2013). Recentemente, a vertente crítica das emoções buscou discutir as relações de ideologia e poder em sua constituição, enfatizando seus aspectos sociais, culturais e políticos (ZEMBYLAS, 2003, 2005). Assim, embasado nas concepções críticas para o ensino de línguas e emoções, buscamos neste estudo de caso discutir como as emoções de uma professora de Inglês de escola pública são formadas, e quais são os fatores que as constituem. Para tanto, analisamos narrativas da professora-participante, que construíram categorias compostas por emoções variadas, tais como: satisfação, medo, insegurança e esperança. Concluímos que a opção pelo ensino crítico de línguas despertou emoções na professora que geram resistência e contestação aos discursos dominantes.
\end{abstract}

PALAVRAS-CHAVE: emoções; perspectiva política-cultural das emoções; ensino crítico de línguas.

\begin{abstract}
Some time ago, the role of emotions in a teacher's life, as well as their impact on the language classroom, was widely neglected (BENESCH, 2012). After the advent of the "affective turn", the field of Applied Linguistics (AL) began to contemplate studies on emotions (BARCELOS, 2015; PAVLENKO, 2013). Recently, the critical aspect of emotions seeks to discuss the relations between ideology and power in its constitution, emphasizing its social, cultural and political aspects (ZEMBYLAS, 2003, 2005). Thus, based on the critical concepts for language teaching and emotions, we seek in this
\end{abstract}


case study to discuss how the emotions of a public school English teacher are formed, and what factors constitute them. For this, we analyzed narratives of the teacher-participant, who built categories, compounding different emotions such as: satisfaction, fear, insecurity and hope. We concluded that the critical language teaching arose teacher's emotions that generate resistance and contestation to the dominant discourses.

KEYWORDS: emotions; political-cultural perspective of emotions; critical language teaching.

\section{Considerações iniciais}

O campo da Linguística Aplicada (LA) tem desenvolvido nos últimos anos pesquisas relevantes sobre a vida de professores de línguas, envolvendo estudos sobre identidade (BARKHUIZEN, 2017), letramentos críticos (MONTE MÓR, 2013), ensino crítico e cidadania (MATTOS, 2013, 2015), dentre outras contribuições importantes para esse campo de investigação. Outro tema de pesquisa que tem chamado a atenção de pesquisadores das ciências sociais e humanas são as emoções dos professores. Essas, têm aumentado de forma gradual nos últimos anos em várias partes do mundo (BARCELOS; ARAGÃO, 2018). No entanto, embora os estudos tenham ganhado visibilidade, pesquisas sobre a relação dessas com a educação crítica de línguas ou justiça social, ainda são pouco realizadas (BOLER; ZEMBYLAS, 2003).

Este artigo propõe discutir as emoções experienciadas por uma professora de Língua Inglesa em seu contexto de escola pública, sob o olhar da Educação Crítica de Línguas e das Perspectivas Críticas das Emoções.

Conforme o exposto, este estudo embasa-se na perspectiva sóciopolítica das emoções (AHEMD, 2004; BENESCH, 2012; BOLER, 1999; ZEMBYLAS, 2003), que advoga que essas são produzidas discursivamente e, portanto, não são internas e individuais, mas são construídas no fazer, através das relações sociais. Constituindo-se dentro da mesma raiz teórica, essa perspectiva alinha-se à vertente crítica para os estudos de línguas, que compreende a língua/linguagem como prática social (BRASIL, 2006; MATTOS, 2013, 2015; MENEZES DE SOUZA, 2011b; MONTE MÓR, 2008). Como aporte metodológico, escolhemos utilizar o estudo de caso com narrativas, por permitir uma análise mais profunda das emoções que a professora-participante experiencia diariamente em seu contexto de trabalho (PAVLENKO, 2013). 
Em seu cotidiano profissional, ensinar uma língua estrangeira envolve uma rede complexa de recursos cognitivos, relacionais e emocionais, pois apenas o conhecimento teórico de ensinar uma língua não é suficiente para lidar com situações complexas que a natureza de seu trabalho envolve (BARCELOS; RUOHOTIE-LYHTY, 2018). Em outras palavras, dentro do contexto escolar, professores experienciam diferentes emoções como raiva, frustração, tristeza, devido a questões variadas: excesso de turmas - em vários estados brasileiros reduziu-se o número de aulas de Inglês, de duas para uma aula por semana -, carga horária excessiva, pouco tempo para planejamento, turmas cheias, salários pouco atrativos, dentre outras questões que demandam um esforço emocional intenso de professores (BARCELOS; RUOHOTIE-LYHTY, 2018). Do ponto de vista das emoções como construção social, os valores das instituições de ensino, de pais de alunos, bem como as crenças e valores pessoais de professores, também influenciam em suas emoções, podendo provocar dissonância e frustração quando seus objetivos não são alcançados ou compreendidos, bem como satisfação quando esses são reconhecidos e valorizados (BARCELOS; RUOHOTIELYHTY, 2018; DENZIN, 2007; ZEMBYLAS, 2003).

A partir de 2006, foi lançada uma proposta curricular para as escolas públicas, objetivando discutir as novas demandas para o ensino de línguas brasileiro. Segundo as Orientações Curriculares para o Ensino Médio de Língua Inglesa (OCEM-LE) (BRASIL, 2006), ensinar Língua Inglesa não se limita apenas aos aspectos gramaticais da língua, mas em preparar o indivíduo para uma sociedade globalizada e plural. Nesse entendimento, o professor precisa assumir uma postura ética "freiriana", ou seja, um comportamento transformador que valoriza o ser humano e o seu contexto social. À vista disso, o papel do professor de línguas exige uma postura crítica frente à sua realidade, pois, na atualidade, o mundo globalizado em que vivemos traz consigo muitas tensões e conflitos e o ensino crítico pode servir como um meio para problematizar as tensões da sociedade atual nas escolas e nas salas de aula de línguas (MENEZES DE SOUZA, 2011a).

Assim, este estudo busca responder os seguintes questionamentos: quais emoções são geradas no contexto de ensino de línguas de uma escola pública? De que maneira a professora de língua inglesa que busca desenvolver um currículo socialmente responsável, gerencia suas emoções em seu cotidiano de trabalho? Para Benesch (2012), estudos sobre emoções em contextos escolares podem auxiliar para que compreendamos quais 
emoções circulam nos contextos escolares e como isso pode afetar a vida dos docentes e, consequentemente, do ensino (BENESCH, 2012). Nos tópicos seguintes, apresentaremos o referencial teórico deste estudo.

\section{Fundamentação teórica: educação crítica de línguas e o professor socialmente responsável}

Vivemos em um mundo cada vez mais interconectado (COPE; KALANTZIS, 2000), firmemente preso à globalização econômica e cultural (KUMARAVADIVELU, 2003). Desse modo, os fluxos de bens, ideias, pessoas e tecnologia produzem diferentes manifestações sociais e culturais, colaborando na construção de uma sociedade globalizada (PENNYCOOK, 1999). Contudo, juntamente com esse fenômeno, também vieram os seus problemas.

Em uma sociedade "global" neoliberal, - cuja herança da colonização perdura até hoje - a disseminação de discursos hegemônicos de grupos dominantes se faz presente, objetivando a manutenção de uma estrutura social injusta e cruel (JUCÁ, 2017). Em decorrência disso, mantém-se, também, um sistema educacional que se propõe a alienar estudantes e professores, ignorando as desigualdades sociais (GIROUX, 1997), bem como um ensino de línguas que reforça estereótipos e aumenta a discriminação às classes menos favorecidas (KUMARAVADIVELU, 2001).

Durante as últimas décadas, pesquisas sobre ensino e formação de professores de línguas, conduzidas pela vertente crítica da LA, problematizam a construção sócio-histórica da manutenção desses discursos dominantes (PENNYCOOK, 1999, RAJAGOPALAN, 2003) que geram "complexos de inferioridade" (RAJAGOPALAN, 2003, p. 68), falta de interesse e frustração, devido à relação binária entre dominantes e dominados (BOLER, 1999; ZEMBYLAS, 2003). Nesse sentido, os estudos críticos têm se preocupado em questionar essas relações injustas de poder, pautando-se em uma agenda progressista de educação de línguas.

Essas orientações progressistas estão presentes nas OCEM-LE (BRASIL, 2006). Esse documento inicialmente sofreu influência do pensamento de Paulo Freire, em especial de sua obra "Pedagogia do oprimido" (2005), na qual esse autor relaciona a consciência crítica do indivíduo à sua libertação. O posicionamento de Paulo Freire (2005) desafia as estruturas desiguais de poder a fim de efetuar mudanças sociais, por meio 
de uma práxis que leve o indivíduo a refletir sobre suas experiências sociais de exclusão. Para esse autor, ao questionar as experiências cotidianas, os "indivíduos excluídos" podem se tornar mais conscientes da situação de opressão em que vivem, como também de suas causas. Nas palavras de Freire (2005, p. 111):

Para que a educação fosse neutra era preciso que não houvesse discordância nenhuma entre as pessoas com relação aos modos de vida individual e social, com relação ao estilo político a ser posto em prática, aos valores a serem encarnados [...] era necessário que toda população nacional aceitasse mesmo que elas, miséria e fome, aqui e fora daqui, são uma fatalidade do fim do século (FREIRE, 2005, p. 111).

Nesse entendimento, os oprimidos são condicionados a perceber a realidade injusta como natural, instalada na sociedade ao longo da história. Essa visão de mundo que Paulo Freire (2005) denomina como "ingênua", pode ser transformada gradualmente por meio da prática da reflexão crítica e ação sobre o mundo para transformá-lo. Para esse educador, o processo de libertação e conscientização nunca pode ser puramente intelectual, mas deve envolver ação. Contudo, não pode, também, limitar-se ao mero ativismo, incluindo uma reflexão séria e responsável sobre a sociedade em que se vive (FREIRE, 2005).

Para Mattos (2013), numa sociedade individualista, competitiva e desigual, a educação para a cidadania e justiça social se torna imprescindível nas salas de aula de Língua Inglesa. Segundo essa autora

[...] um tipo de educação que tenha por objetivo a formação da cidadania do educando, com vistas a obter relações sociais mais igualitárias não pode deixar de fora a questão da inclusão social, frente a uma inquestionável realidade de exclusão no cenário brasileiro (MATTOS, 2015, p. 259).

Além disso, historicamente, há uma geração, fruto de uma educação pautada na ideia de cidadania responsável, que acaba reproduzindo um comportamento conformista e obediente (MATTOS, 2011). Por essa razão, é necessário que a escola ofereça momentos de reflexão que ajudem os alunos a desenvolver uma cidadania participativa. Isso pode ser estimulado por meio de temas críticos que abrangem a sociedade atual (MATTOS, 2011). 
Ao situar a escola pública como um local socialmente constituído para o desenvolvimento de cidadania, a "dimensão crítica do letramento permite que os indivíduos participem de suas comunidades de forma efetiva e produtiva" (MATTOS, 2015, p. 104), pois o ensino de línguas não pode se limitar ao ensino instrumental da língua, mas deve reconhecer que este ensino produz subjetividades, modos de ser e estar no mundo (BRASIL, 2006). Conforme as OCEM-LE (BRASIL, 2006, p. 90), o enfoque do ensino de LI deve considerar a construção de cidadania, visto que as "necessidades da sociedade atual apontam para um trabalho educacional em que as disciplinas do currículo escolar se tornam meios [para] a formação de indivíduos". Nesse contexto, as práticas de letramento crítico direcionadas ao ensino de cidadania podem ajudar a refletir sobre como as emoções influenciam na constituição das ações do professor e das relações sociais dentro e fora de sala de aula (MATTOS, 2015).

Por essa ótica, Menezes de Souza (2011b) alega que, na atualidade, a escola necessita preparar o indivíduo para o novo milênio, pois, vivemos em um mundo cheio de conflitos, diferenças, posições, exigindo do professor uma pedagogia que proponha reflexão sobre a sociedade de forma crítica. E isso "pode ser alcançado através do letramento crítico" (p. 128). Menezes de Souza (2011b) enfatiza que ao apontar o leitor como sujeito crítico, Paulo Freire busca a relação entre a "palavra" e "mundo", que perpassa o processo de aprender a escutar/ouvir. A leitura de mundo de forma incontestável não cabe dentro da perspectiva do letramento crítico. Segundo esse autor, para se compreender o mundo é preciso estar ciente de sua constituição sócio-política e histórica, visto que "cada produção de significação de cada comunidade adquire sua validade apenas em dado momento histórico desta comunidade" (MENEZES DE SOUZA, 2011a, p. 136). Assim, nesse exercício de aprender a escutar as próprias leituras e se colocar como um construtor do mundo em que vive, podemos também criar uma possiblidade de convivência mais responsável e justa.

\subsection{Por que investigar emoções?}

O mundo em que vivemos é construído e permeado por emoções (AHMED, 2004). No entanto, essas foram negligenciadas na esfera social e pública, sendo pouco estimuladas em cenários acadêmicos durante vários anos (BOLER, 1999). Essa desvalorização ocorreu devido à predominância 
do pensamento racional, associando as emoções como algo inferior ou “irracional” (BOLER, 1999; HOCHSCHILD, 1979, 1983).

Nesse contexto, a partir dos anos 90, estudos com foco nas emoções no âmbito educacional começaram a emergir, evidenciando-se mais no campo da psicologia, tendo como um dos principais nomes Daniel Goleman (1995) e seus estudos sobre inteligência emocional. Aos poucos outras áreas como a linguística, a sociologia, a filosofia, a geografia, dentre outras, ampliaram a discussão sobre emoções em contextos escolares e formação de professores, buscando expandir-se para além da tradição da psicologia cognitivista, ao incorporar questões sociais e culturais, a fim de valorizar a dinâmica multifacetada e sofisticada das emoções humanas (AGUDO, 2018).

Beneficiando-se de um conjunto interdisciplinar de pesquisas, as publicações geradas no âmbito do ensino ganharam destaque a partir dos anos 90. Segundo Day e Chi-kin Lee (2011), os primeiros estudos sobre emoções e ensino foram publicados em 1996, no Cambridge Journal of Education. Em seguida, em 2005, o periódico Teaching and Teacher Education lançou uma edição especial sobre emoções de professores e mudança educacional (DAY; CHI-KIN-LEE, 2011). Esses autores afirmam que há um número pequeno de obras publicadas na área da educação sobre emoções, citando algumas como o Handbook of the Sociology of Emotion editado por Stets e Turner em 2006, Emotion and Education, editado por Shultz e Pekrun em 2007, além da obra Advances in teacher emotion research: the impact on teacher's lives, editado por Schutz e Zembylas em 2009, sendo essa última focada em diferentes lentes teóricas e metodológicas sobre emoções (DAY; CHI-KINLEE, 2011).

Em relação aos temas abordados nessas obras, os autores discutem reformas educacionais, construção de identidade, testes de alta-performance, práticas pedagógicas, dentre outros que problematizam os efeitos das emoções na vida de professores (DAY; CHI-KIN-LEE, 2011; SCHUTZ; ZEMBYLAS, 2009). No ensino de línguas, Juan de Dios Martinez Agudo publicou uma coletânea de artigos sobre "Emotions in Second Language Teaching: Theory, Research and Teacher Education", requerendo mais pesquisas específicas para a área de línguas.

Apesar do crescente interesse acadêmico pelas emoções, não existe consenso geral sobre o seu conceito, pois essas não são um fenômeno simples de ser explicado (BARCELOS; ARAGÃO, 2018; BENESCH, 2012). Para Barcelos (2015), as emoções são construções dinâmicas de 
uma rede complexa que colorem nossas percepções e influencia nossas ações. Benesch (2012) alega que as emoções são interativas, contextuais, sociais e incorporadas. Denzin (1984) definiu as emoções como práticas emocionais situadas e incorporadas nas interações com os outros. De acordo com Lutz (1988), as emoções são artefatos culturais e atos morais que negociam aspectos da realidade social. Embora esses pesquisadores sigam perspectivas teóricas distintas, todos reconhecem a importância de se produzir investigações com emoções para compreender a sociedade e as relações sociais entre os indivíduos em diversos contextos sociais. Como explicado na introdução deste texto, essa pesquisa embasa-se na perspectiva político-cultural das emoções, que discutiremos a seguir.

\subsection{Perspectivas político-culturais das emoções}

Nos últimos trinta anos, o interesse acadêmico pelas emoções vem ganhando espaço, trazendo à baila pesquisas sobre emoções na vida pública, sobretudo as relacionadas a movimentos sociais e políticos (AHEMD, 2004; ABU-LUGHOD; LUTZ, 1990). Historicamente, as emoções têm sido consideradas como internas e pessoais (BOLER, 1999). Porém, recentemente, pesquisadores alegam que essas não podem ser distanciadas da vida social e cultural dos indivíduos (AHMED, 2004; BENESCH, 2017; ZEMBYLAS, 2003, 2007). Nesse sentido, as correntes críticas das emoções alegam que essas não são instintivas nem biológicas, mas social e culturalmente construídas (ABU-LUGHOD; LUTZ, 1990). Nas palavras de Lutz (1988, p. 5), a emoção é "fundamentalmente estruturada por sistemas culturais particulares, bem como ambientes sociais e materiais específicos. (...) A experiência emocional não é pré-cultural, mas principalmente cultural".

O enfoque para as emoções teve como marco inicial o que Pavlenko (2013) denominou por virada "afetiva". Isso ocorreu nos anos 90, objetivando desafiar a predominância de pesquisas sobre cognição. Igualmente às outras "viradas" (linguísticas, críticas e culturais), a virada afetiva recebeu colaborações de diferentes perspectivas, como a dos estudos feministas e pós-estruturalistas, os quais se propuseram a questionar os regimes de "poder" e "verdade" sobre as emoções existentes em sociedade (ABU-LUGHOD; LUTZ, 1990). Essas visões críticas delineiam as emoções como construídas social e culturalmente, isto é, são sempre experienciadas, compreendidas e nomeadas por meio de processos sociais e culturais 
e, portanto, são, em maior ou menor grau, aprendidas e não herdadas (ZEMBYLAS, 2007).

Dentro dessas perspectivas críticas que Ahmed (2004) e Benesch (2019) também chamam de político-culturais, existe uma sobreposição entre os fatores políticos, sociais e culturais na construção das emoções. Para a maioria dos autores que seguem essa vertente, a identidade dos indivíduos é constantemente constituída em contextos de poder e ideologia (AHMED, 2004; BENESCH, 2017; ZEMBYLAS, 2003).

Opondo-se à visão crítica estruturalista das emoções - na qual as emoções dos indivíduos estão diretamente associadas à sua posição no sistema social -, a visão crítica-pós-estruturalista compreende que os discursos sobre emoções constroem ativamente conhecimentos sobre o "eu" e a sociedade, estando implicados em um jogo do poder, sob um sistema de hierarquia social em constante mudança (ABU-LUGHOD; LUTZ, 1990). Desse modo, as emoções são fenômenos intersubjetivos e não individuais, constituídos nas relações de poder entre as pessoas.

Nesse entendimento, a perspectiva político-cultural das emoções destaca as maneiras pelas quais as emoções se constituem nas interações sociais, sendo continuamente (re)criadas, contestadas, interpretadas por meio de discursos de poder, incorporadas e modeladas por discursos múltiplos e contraditórios (TRACY; TRETHEWEY, 2005). Em outras palavras, as emoções que pessoas dizem e/ou fazem não são simplesmente uma consequência da escolha ou preferência dos indivíduos, mas uma articulação de normas culturais e sociais mais amplas. Essas normas são construídas a partir de processos de dominação, contestação e resistência, sendo reflexos do controle social em sociedade (ZEMBYLAS, 2003). Portanto, essa perspectiva permite que os pesquisadores discutam as emoções dos professores para além da psicologização dessas, ou apenas como estruturas hierárquicas que moldam o indivíduo. As emoções não são específicas, nem meramente o efeito de estruturas externas, mas são construídas pela compreensão, experiência e desempenho dessas pelos docentes em contextos escolares.

\section{Estudo de caso com narrativas}

Nosso objetivo foi investigar e analisar as emoções experienciadas por uma professora de Língua Inglesa de escola pública, à luz das perspectivas 
críticas do ensino de línguas e das emoções. Para tanto, optamos por desenvolver um estudo de caso, por essa metodologia oferecer meios de se obter uma rica contextualização, bem como executar uma análise profunda e indutiva de dados de um pequeno conjunto de participantes (DUFF, 2012). Bruner (1990) salienta que o estudo de caso possui semelhanças com a construção de narrativas, pois, para se compreender o "todo" de um caso, é necessário entender suas histórias.

Conforme Clandinin e Connelly (2011), as narrativas são um modo de compreensão das experiências dos professores. Corroborando essas autoras, Mattos (2009) advoga que as vozes de professores, contadas em suas histórias de vida, são fundamentais para se compreender o ensino (MATTOS, 2009). Sendo assim, as narrativas podem servir como um meio para "obter acesso a informações cruciais da pesquisa, as quais, de outra forma, poderiam ser inacessíveis ao pesquisador" (MATTOS, 2009, p. 32).

Em relação ao uso de narrativas para pesquisas com emoções, Kelchtermans (2016) explica que a compreensão do pesquisador implica em uma leitura "adequada" das emoções inerentes ao texto "emotivo". Em outras palavras, a construção da narrativa não é primariamente um processo individual ou peculiar, embora as histórias possam diferir consideravelmente dependendo de quem está falando. Contudo, é necessário levar em consideração o resultado da percepção da interação entre o narrador e o "leitor", bem como o contexto, entendido tanto no sentido temporal quanto espacial (KELCHTERMANS, 2016).

Por acreditar que as narrativas das experiências da participante possam expandir significativamente o entendimento de suas emoções, colhemos narrativas de uma professora-participante durante os três primeiros meses do segundo semestre do ano de 2018 e no mês de novembro de 2019. Como instrumentos de geração de dados, lançamos mão de diários-reflexivos, entrevistas semiestruturadas e conversas informais via aplicativo de mensagens. Durante os procedimentos de geração de dados, a participante foi instruída a gravar livremente seus diários sobre sua rotina e suas emoções ligadas ao ensino. Em relação à entrevista-narrativa, apresentamos perguntas norteadoras que foram ampliadas de acordo com o desenrolar da entrevista.

Para analisar os dados gerados neste estudo, utilizamos um procedimento baseado na abordagem denominada "Grounded Theory" (CORBIN; STRAUSS, 1990; DORNEY, 2007). Apesar de o nome conter o termo "theory", a abordagem não se refere a uma teoria em si, mas a um 
método para análise de dados. Conforme Corbin e Strauss (1990, 2007), o procedimento dessa abordagem consiste em três etapas: codificação aberta, codificação axial e codificação seletiva. A primeira relaciona-se a uma tentativa de analisar os dados, onde esses são segmentados. Partes do texto recebem códigos mais abstratos e conceituais do que descritivos. $\mathrm{O}$ foco nessa primeira etapa é ler os dados e questionar o significado do que está sendo lido (CORBIN; STRAUSS, 2007). O segundo passo, codificação axial, trata-se de um processo de codificação mais abstrato, no qual o pesquisador faz conexões entre categorias para integrá-las a conceitos mais gerais. A etapa final da análise, a codificação seletiva, diz respeito às categorias principais identificadas para integrar os dados processados (CORBIN; STRAUSS, 2007).

Os procedimentos apresentados acima foram seguidos em todos os instrumentos utilizados para gerar dados e, ao final, foram elencadas três categorias principais inter-relacionadas que serão apresentadas no tópico de discussão de dados.

\section{Participante e contexto}

A professora-participante é docente efetiva da disciplina de Língua Inglesa da rede municipal de educação, na cidade de Belo Horizonte, estado de Minas Gerais e possui aproximadamente dezenove anos de experiência. Atualmente, a participante ministra aulas de Inglês no Ensino Fundamental II, de sétimo ao nono ano, em uma escola localizada em um bairro da zona norte de Belo Horizonte, além de lecionar em um curso livre de Inglês. Além disso, a professora-participante já possui mestrado em Literatura e está cursando doutorado em Estudos Linguísticos em uma Universidade pública no estado de Minas Gerais. Para garantir o anonimato da participante, foi atribuído a ela o codinome "Maria".

\section{Discussão e análise de dados}

Neste tópico apresentamos as análises e as discussões da constituição das emoções da professora-participante em seu contexto de trabalho e sua relação com a perspectiva crítica do ensino de línguas. Para tanto, representaremos a ideia central de cada tópico com as falas de Maria: " $A$ gente quer desenvolver nos alunos a formação crítica [...] é muito gratificante"; "A gente fica com medo [...] como vamos desenvolver um trabalho voltado para os letramentos 
críticos?"; "O que move a gente é saber que háperspectiva de mudança no futuro [...] que ainda há esperança".

\section{1 “A gente quer desenvolver nos alunos a formação crítica [...] é muito gratificante".}

Historicamente, a formação de professores no Brasil foi marcada por um ensino de línguas cujo foco recaía, sobretudo, no desenvolvimento de competências e habilidades de línguas estrangeiras (JUCÁ, 2017, p. 80). Em relação às abordagens e métodos de ensino, foram utilizados desde a abordagem tradicional à comunicativa, sendo essa última considerada uma das mais importantes nos anos 90, pois a língua inglesa passava a ser utilizada para diferentes propósitos comunicativos (MATTOS; VALÉRIO, 2010). Segundo Mattos e Valério (2010), apesar de seu objetivo principal ser a comunicação na língua-alvo, essa abordagem não estimula a emancipação do sujeito, tampouco propõe que os professores utilizem materiais que reflitam a realidade injusta e desigual da sociedade em que vivemos (MATTOS; VALÉRIO, 2010). Contudo, desde a promulgação das OCEM-LE (BRASIL, 2006) termos como cidadania, justiça social, formação crítica, emancipação do sujeito, pluralidade, diversidade passaram a fazer parte do contexto de ensino de línguas brasileiro, convidando o professor de LI a uma reflexão sobre questões sociais e políticas em seu local trabalho.

Neste estudo, compreendemos que ensinar é uma prática emocional (HARGREAVES, 2001) e uma prática social (BRASIL, 2006). Isto é, os acontecimentos sociais estão interligados com a sala de aula e influenciam e são influenciados pelas emoções (ZEMBYLAS, 2003). Para Denzin (2009, p. 5), as emoções desempenham um papel fundamental no engajamento de professores em perspectivas críticas de ensino, pois exigem paixão com a educação e "compromisso com a justiça social para o processo de aprendizagem”. Esses fatores podem ser observados na fala de Maria, ao mencionar que:

[...] para mim, ensinar inglês é mais que ensinar a língua, é discutir cidadania, trabalhar questões que sejam relevantes para a sociedade, (...) eu gosto de trabalhar com ele (professor de geografia), porque, cada vez mais, eu estou distanciando dessa forma tradicional de ensinar gramática, a gente ficava frustrada. Então, eu prefiro pensar em temas e trabalhar junto com outro professor, igual a gente fez no 
projeto com a professora de artes, o planejamento ele muda o tempo todo, né. É muito dinâmico, para mim. (Entrevistanarrativa, 19/12/2018).

Desse modo, Maria parece alinhar-se aos princípios fundantes das OCEM-LE (BRASIL, 2006). Esse documento visa provocar uma ruptura com os valores hegemônicos e oferecer uma educação voltada para a cidadania e justiça social. Tendo como base os letramentos críticos, as OCEM-LE (BRASIL, 2006) colocam em evidência a necessidade de se problematizar sobre as mudanças ocorridas na sociedade globalizada e com muita tecnologia (LANKSHEAR; KNOBEL, 2003, apud MATTOS, 2011). Segundo Mattos (2011), as OCEM-LE (BRASIL, 2006) convidam os professores de Línguas Estrangeiras a refletirem sobre o que significa ensinar Inglês na escola pública, sugerindo que discutam para além da gramática e incluam questões que envolvam diversidade cultural, cidadania, justiça social, dentre outras (MATTOS, 2011). Assim, Maria parece ter esse mesmo propósito ao optar por trabalhar com projetos diversificados em suas aulas. Vejamos no excerto a seguir:

Mas em relação a nossa aula de inglês! Estou me sentindo como se eu fosse uma formiguinha. Fazendo trabalho [...] Assim, de um tanto de gente [...] no nono ano a gente tá falando das metas da ONU. Fazer uma conexão com as questões que a gente está trabalhando [...] outras duas metas que é igualdade de gênero e educação primária universal para todos. Mas no sétimo ano, os meninos são menores e a gente está só em um tema mesmo. Esta da jornada literária que é mostrar a escola, meu espaço, meu lugar, eu pertenço. [...] Como tem um projeto sobre "bullying" na escola, interdisciplinar, eles estão mostrando a escola para um aluno estrangeiro eu pedi para eles colocarem países não muito conhecidos que falam inglês. (Diário-reflexivo, 17/09/2018).

Observamos que Maria parece não seguir o modelo tradicional de ensino que foca totalmente na gramática ou na pronúncia. Ao invés disso, ela escolhe temas relevantes para sociedade atual para serem discutidos em suas aulas, como bullying e igualdade de gênero, além de mostrar aos alunos que a língua inglesa não é falada apenas nos Estados Unidos e Inglaterra, como é enfatizado pela herança colonial de ensino de línguas (JUCÁ, 2017). 
Embora ela mostre satisfação pelas suas escolhas pedagógicas, ela também demonstra cansaço ao dizer que está se sentindo como uma formiguinha, pois a sua rotina exaustiva exige muito empenho e dedicação. Maria possui apenas uma aula de Inglês por turma, aumentando ainda mais a sua carga de trabalho, com muitas provas e atividades para corrigir, mais alunos para atender, dentre outras demandas do seu dia a dia. Além disso, Maria é a única professora de Inglês da escola e esse fator também faz com ela sinta que a sua responsabilidade seja maior, visto que não há outra professora formada na área para compartilhar seus projetos. Contudo, Maria busca auxílio e parcerias com professores de outras disciplinas.

Apesar de Maria se sentir como "uma formiguinha", alguns dos fatores que possivelmente colaboraram para que ela não perdesse o entusiasmo pode ter sido o apoio dos colegas, da escola, bem como dos pequenos resultados positivos de seu trabalho. Em suas palavras:

O letramento crítico faz parte da escola. A gente (a escola) quer desenvolver nos alunos a formação crítica. De ele (aluno) saber o seu papel na sociedade, saber agir se posicionar, aprender línguas, que é o que a gente tá focando aqui. Aprender nesse caso a língua inglesa [...] como se você tivesse assim um passaporte para cidadania [...] assim que eu vejo isso acontecendo, o crescimento dos alunos, mesmo quando eles apresentam trabalhos [...] (como) a feira de cultura que a gente teve, e os alunos indo numa casa de apoio junto com o (professor de geografia), querendo trabalhar com voluntariado depois disso. [...] É muito gratificante. (Entrevista-narrativa, 19/12/2018).

Mais uma vez, Maria confirma a sua visão de ensino de língua como prática social e com propósitos de desenvolver nos alunos uma postura reflexiva e crítica, por meio da perspectiva do letramento crítico. Além disso, a escola estimula esse modelo de ensino, ajustando-se aos propósitos pedagógicos da professora.

Como explicitado por Mattos (2011)fbictem DATA), o ensino de línguas com foco em cidadania motiva o aluno a agir e a se posicionar em sociedade, vindo ao encontro do desejo de Maria, lhe proporcionado satisfação. Quanto a isso, a professora-participante explica nesse excerto a respeito da realização de uma feira pedagógica que culminou na visita dos alunos a uma casa de apoio às crianças e jovens em situação de vulnerabilidade. 
Embora Maria não tenha detalhado o que eles desenvolveram durante esse projeto, essa atividade parece ter despertado em alguns alunos a vontade de se tornar voluntário. Esse fator deixou Maria satisfeita, pois afirma que o projeto foi muito gratificante.

Entendemos assim que a representação de ensino de línguas para essa professora vai além de ensinar a estrutura da língua em si, mas ensinar para provocar discussões críticas e dar oportunidade para que seus alunos se posicionem como cidadãos conscientes de seu papel social. Como exposto anteriormente, Maria possui autonomia para desenvolver um trabalho com a perspectiva crítica, estando seus valores pessoais e objetivos profissionais em sintonia com os valores da escola. Contudo, a escolha em seguir essa perspectiva também trouxe momentos de tensão como o cansaço, pois acarreta mais trabalho na preparação das aulas e, em alguns momentos, a emoção do medo, que será debatida na próxima subseção.

\section{2 "A gente fica com medo [...] como vamos desenvolver um trabalho voltado para os letramentos críticos."}

De acordo com Benesch (2012), a perspectiva crítica das emoções para o ensino de línguas se interessa, sobretudo, pelas emoções consideradas "ruins", tais como desesperança, apatia, ansiedade, medo, dentre outras, a fim de compreender as formas de contestação e resistência de professores aos discursos dominantes. No entanto, dentro de contextos escolares, essas emoções são pouco debatidas com professores e, muitas vezes, evitadas ou escondidas por eles (BENESCH, 2012), devido a questões culturais mais amplas em torno das emoções e do próprio magistério. Segundo essa vertente, o poder não apenas constrange, mas também assujeita o indivíduo, produzindo "novas" subjetividades (ZEMBYLAS, 2007). Assim, conforme os padrões morais da sociedade, certas verdades sobre o que significa ser professor ou qual a sua função é, são coisas construídas, podendo causar desconforto ao docente que possui um comportamento desviante (BENESCH, 2012). Em outras palavras, se a conduta dos professores não estiver de acordo com as normas sociais, certos conflitos podem ser produzidos e gerar emoções tais como medo e angústia, podendo sofrer mudanças, visto que na perspectiva pós-estruturalista, as emoções são dinâmicas e não linearizadas.

$\mathrm{Na}$ escola de Maria, um fato que ocorrera com um de seus colegas fez surgir a emoção do medo. A professora-participante mencionou que um 
professor de outra disciplina problematizou a respeito da pobreza que existe nos Estados Unidos em uma de suas salas de aula. Por conta disso, a mãe de um aluno questionou a atividade, pois aquele enfatizou as desigualdades sociais nos Estados Unidos e ela discordou disso. Vejamos esse fato no trecho a seguir:

Nesse dia aconteceu um episódio. Lembra que eu comentei que o professor de (nome da disciplina) estava lendo um texto da UNESCO e uma mãe escreveu uma carta de duas páginas criticando a postura da UNESCO, que é de esquerda, que não tem um posicionamento neutro e ela querendo fonte a respeito dos dados citados porque estava falando do aumento da pobreza nos Estados Unidos e ela não concorda e tal (Diário-reflexivo, 05/11/2018).

É importante salientar que, de acordo com a visão do letramento crítico, esclarecer as fontes trabalhadas em sala de aula ou discordar da opinião do texto é perfeitamente aceitável e estimulado, pois essa perspectiva se propõe a desconstruir verdades e estimular a prática da dúvida (MENEZES DE SOUSA, 2011a). Porém, a mãe julgou como inadequado e rotulou a ONU de ter uma posição de "esquerda", sendo o real motivo que a levou a reclamar da aula do professor. $\mathrm{O}$ fato de essa mãe colocar em dúvida o trabalho do professor, soa como uma forma de intimidação. Pois, atualmente, para alguns grupos sociais, a palavra "esquerda" possui uma forte carga pejorativa em seu sentido, apesar da ONU não representar o discurso de esquerda.

Se voltarmos no tempo, historicamente, vivemos em nosso país um período marcado pela repressão vivenciada por muitos brasileiros na época da Ditadura Miliar, que teve o seu início em 1964. Esse período durou mais de 20 anos e "a memória dessa época certamente ajudou a moldar várias atitudes individuais e comportamentos e costumes culturais" (MATTOS; CAETANO, 2019, p. 179). Nessa época, a manifestação de opiniões contrárias ao governo era proibida e, como consequência, "as vozes da população foram silenciadas em inúmeros contextos” (MATTOS, 2015, p. 268). Essa tentativa de silenciamento cria a experiência do medo, impedindo qualquer análise crítica e aumentando as fronteiras entre o "eu" e o "nós" (AHMED, 2004). Como afirma Ahmed (2004), a produção da emoção do medo atende a fins políticos e econômicos, pois se torna normatizada no 
cotidiano do professor, podendo levá-lo a ceder ou não às pressões externas, mas, certamente, lhe causa sofrimento.

Nesse contexto, Maria revelou que:

Quando a gente quer passar uma mensagem, por exemplo, a gente não pode falar tão abertamente [.. e ainda dizem que estamos doutrinando. Isso afeta a gente $[\ldots]$ a gente fica com medo! Agora eu quero ver como vamos desenvolver trabalho voltado para letramento crítico e questões importantes [...] os pais vão estranhar. Afinal de contas eles pensam que é só ensinar a língua e não falar sobre nenhum outro assunto. Vamos ver como vai ficar (Entrevista-narrativa, 19/12/2018).

Entendemos, a partir do excerto, que a tensão também pode ter sido gerada pela crença, que muitas pessoas possuem, de que a escola deve somente "ensinar" técnicas instrumentais, a memorizar fatos e não provocar no aluno o desejo por reflexões críticas sobre a sociedade em que vivemos (BRASIL, 2006). Assim, ao adotar a posição de professor socialmente responsável, Maria nega o "outro" modelo de professor "neutro" e alienado, distanciando-se de discursos neoliberais e tradicionais de ensino que visam apenas a preparação do aluno para o mercado de trabalho e não o processo de formação de cidadania e (trans)formação social (MATTOS, 2011).

Contudo, Maria também se autoquestiona sobre o seu papel, pois o efeito de atitudes hostis e impositivas da sociedade atual, em especial contra o estímulo da criticidade na escola, como, por exemplo, os discursos do projeto Escola Sem Partido, criam ansiedade e medo sobre o seu trabalho docente:

Agora a gente não sabe como vai ser o nosso papel [..] Agora a gente está com medo! [...] Eu vou te falar estou muito ansiosa com essa situação [..] (Diário-reflexivo, 23/10/2018).

Dentro da visão sócio-política das emoções, a emoção do medo se estabelece nas relações de poder e cultura, como uma forma de controle (AHMED, 2004). Essa emoção como política afetiva não nasce nos indivíduos e é direcionada para outros corpos, mas cria limites entre "o que sou" e "o que não sou", por meio do efeito de se afastar de um objeto que ameaça "o que sou” (AHMED, 2004). Parafraseando o filósofo Heiddeger, Ahmed (2004) afirma que quanto mais eu desconheço outro, mais eu o 
temo. Melhor dizendo, os estereótipos criados para gerar a emoção do medo podem causar exclusão de certos grupos sociais, como de imigrantes, que são vistos como ameaça às pessoas locais, ou corpos "negros", considerados como marginais (AHMED, 2004). Essa autora advoga que "o medo envolve encolher a mobilidade do corpo [...] O medo trabalha para contê-lo (corpo), de modo a ocupar menos espaço [...] as emoções trabalham para alinhar o espaço da corporeidade com o social” (AHMED, 2004, p. 69). Desse modo, a emoção do medo tende a fortalecer a manutenção dos discursos dominantes, os quais operam para estabelecer normas de controle sobre os corpos (AHMED, 2004).

Assim, as emoções dos professores são constituídas em contextos político-culturais, por meio de relações de poder e resistência. Para tanto, faz-se necessário levar em consideração as maneiras pelas quais as políticas institucionais e discursos "profissionais" criam regras emocionais, valorizando comportamentos emocionais "apropriados" (BENESCH, 2012). Os discursos da sociedade que exigem um modelo de educação "neutra" desconsideram a função social da escola e produzem emoções "negativas" em Maria, gerando insegurança e medo de poder atuar com liberdade e responsabilidade social em seu local de trabalho.

Para Zembylas e Chubbuck (2009), a emoção do medo se constitui como resultado de lutas sociais e políticas em torno de questões de injustiça e, da mesma forma, desenvolvem-se emoções de esperança, amor e paixão em relação às concepções e práticas de justiça social. Assim, como contraponto à emoção do medo, Maria também expressa a emoção da esperança, a qual discutiremos no subtópico seguinte.

\section{3 “O que move a gente é saber que há perspectiva de mudança no futuro [...] que ainda há esperança."}

Emoções contraditórias de satisfação, insegurança, medo e esperança estão presentes na vida de Maria. Para alguns pesquisadores, emoções como autoestima, confiança, esperança e otimismo aparecem quando os professores sentem que suas ações são consistentes com seus valores e crenças (ARAGÃO, 2011; BARCELOS, 2013; NIAS, 1996). Para a professora-participante o ensino crítico traz esperança na mudança para uma sociedade melhor. Em suas palavras: 
Acho que o que me leva a trabalhar com a perspectiva crítica é a esperança mesmo, esperança de transformação da sociedade, daquele grupo de alunos, plantar uma sementinha que possa germinar depois. Eu acredito que nas aulas de inglês a gente pode fazer ali, mesmo sendo aula de inglês, mesmo que muitos alunos não vão entender por que a gente usa a crítica na aula de inglês, mas é a esperança sim, de que a gente possa falar abertamente sobre qualquer assunto [...] o que move a gente é saber que há perspectiva de mudança no futuro de acreditar que ainda há esperança, que há resistência. (Conversa informal por um aplicativo de mensagens, 12/11/2018.

A esperança, representada na fala de Maria, influencia em suas escolhas em sua sala de aula, pois desafia a manutenção do status quo, que tenta impedir a agência do professor. Observamos que a professoraparticipante não é alienada, isto é, não é apática às forças dominantes, mas move-se para agir ativamente em sociedade. Nesse sentido, essa atitude de Maria concorda com o pensamento de Paulo Freire (2005) sobre a emoção da esperança. Freire (2005) alega que os professores precisam ter esperança do verbo "esperançar" e não do verbo "esperar". Isso porque o "esperar" é tão somente uma espera, mas esperançar é mais do que isso, "não é, porém, um cruzar de braços e esperar. Movo-me na esperança enquanto luto e, se luto com esperança, espero" (FREIRE, 2005, p. 95). Esse conceito de esperança freiriano parece inspirar Maria, pois é uma professora engajada em sua profissão. Ela menciona:

Eu milito muito pela educação pública. Trabalho, também, na educação privada, num cursinho. Mas, quando eu estou atuando na educação pública, eu me vejo muito naqueles meninos também. Tenho muito orgulho de dizer que eu nunca estudei numa escola particular, na rede privada. [...] Eu fiquei muito feliz que a gente teve quatro alunos aprovados no Ensino Médio Tecnológico Federal. [...] Que insegurança é essa da gente não acreditar na educação pública (Entrevistanarrativa, 19/12/2018).

Compreendemos aqui que esperança serve de base para permanecer ativamente envolvida em sua profissão. O orgulho de ser fruto da educação pública parece encorajá-la a ter atitudes positivas em relação à escola pública, bem como demonstrar empatia por seus alunos, mesmo estando em circunstâncias difíceis. A esperança pode ser uma força que conduz os 
professores na direção de acreditar que é possível promover um futuro melhor para a educação, colocando o docente em uma posição de agente (MATTOS, 2009). Contudo, Maria também demonstra alinhar-se aos discursos neoliberais de eficiência e competitividade. Aqui, a emoção de contentamento em relação aos êxitos da escola pública, valorizam os discursos que excluem a maioria dos estudantes de classes menos favorecidas, demonstrando um paradoxo em suas emoções em relação ao ensino socialmente responsável e justo.

Por fim, a esperança traz também otimismo em dias melhores:

[...] É muita coisa que passa na minha cabeça ao mesmo tempo, mas acho que as coisas irão se acertar. Temos que ter esperança de que dias melhores virão (Diário-reflexivo, 23/10/2018).

Apesar de todas das dificuldades, Maria se mostra confiante no futuro. Revela esperança em dias melhores, demonstrando o seu comprometimento com a educação pública. Assim, em meio a uma sociedade que desvaloriza o pensamento crítico e exclui grande parte de nossos jovens, a esperança é uma das emoções mais relevantes para o processo de resistência das relações de poder existentes na educação e na sociedade de modo geral.

\section{Considerações finais}

Neste estudo, nos propusemos a discutir a constituição das emoções de uma professora de Inglês de escola pública, segundo a corrente político-cultural das emoções e pelo viés das perspectivas críticas de ensino de línguas. A corrente político-cultual das emoções advoga que a sua constituição se dá por meio de um processo contínuo e dinâmico, construídas e reconstruídas, historicamente dentro de uma cultura, por meio de relações de poder (AHMED, 2004; BENESCH, 2012, ZEMBYLAS, 2003). A cultura da escola, da sala de aula e da comunidade escolar produz fatores que influenciam na construção e gerenciamento das emoções de professores.

Em sua essência, a concepção crítica para o ensino de línguas compreende a língua como uma prática social e, portanto, está diretamente relacionada com a construção de sujeitos. Nos dias atuais, optar por uma perspectiva de trabalho que privilegie práticas de letramento crítico e a criticidade nos alunos, não só na LI, mas em qualquer disciplina, implica em ter que lidar com discursos contrários que provocam tensões e emoções 
"ruins", como aconteceu com a professora Maria. Como visto, a relação complexa de suas emoções varia entre satisfação, cansaço, ansiedade, medo, esperança, (re)constituindo-se continuamente na sua subjetividade.

A cultura da sociedade neoliberal dedica-se a assujeitar os professores em sujeitos produtivos, sobrecarregando-os com várias atribuições diárias, as quais já foram destacadas por alguns autores (JUCÁ, 2017). Apesar disso, Maria escolheu produzir o seu próprio planejamento de aula em forma de projetos, mesmo se sobrecarregando ainda mais. Ao mesmo tempo, a professora-participante sente-se satisfeita por poder trabalhar em uma linha progressista, na qual ela acredita ser a mais adequada para a construção de um mundo mais justo. Quanto às emoções de medo e esperança, compreendemos que ambas estão entrelaçadas, pois o medo sinaliza que a professora não concorda com posturas antidemocráticas na escola e a esperança lhe conduz à ação contínua em seus propósitos de ensino de línguas.

Desse modo, podemos afirmar que as emoções relacionadas aos letramentos críticos são emoções de resistência a uma cultura neoliberal e colonial, que não quer perder o seu lugar de poder. Para Menezes de Souza (2011a) e Monte Mór (2013), o letramento crítico não é necessariamente uma abordagem de ensino e sim uma postura crítica em suas ações cotidianas como professor. Para tanto, isso envolve uma ética docente que busca desestabilizar os discursos dominantes que produzem e perpetuam as desigualdades sociais, bem como lutar pela desnaturalização de situações de opressão. Nesse sentido, as emoções demonstradas por Maria são um sinal de que tanto a postura quanto a ação de professores são afetadas por emoções e essas (re)produzem práticas sociais (ZEMBYLAS, 2007).

Reiteramos que a discussão das emoções pelo viés político e cultural pode servir como uma forma de se compreender quais são as forças sociais que geram emoções ruins (BENESCH, 2017) nos professores. Sugerimos, então, que os cursos de formação de professores voltem o seu olhar para as emoções no ensino de línguas, especialmente aquelas consideradas "ruins", pois são um sinal de que algo precisa ser problematizado, a fim de contribuir para que mais professores não desistam da sua profissão. Da mesma forma que Menezes de Souza (2011a) sugere a escuta de si falando do outro, "ouvir, se ouvindo", sugerimos também uma escuta ativa para as nossas emoções, criando a prática de se perguntar por 
que eu sinto o que eu sinto pelo outro, por que o outro sente dessa forma, como eu me vejo sentindo da forma que sinto, como uma possibilidade de diálogo e melhor conviver com as diferenças.

\section{Referências}

ABU-LUGHOD, L.; LUTZ, C. A. Introduction: Emotion, Discourse, and the Politics of Everyday Life. In: LUTZ, C.; ABU-LUGHOD, L. (ed.). Language and the Politics of Emotion. Cambridge: Cambridge University Press, 1990. p. 1-23.

AGUDO, J. D. M. Emotions in Second Language Teaching. Theory, Research and Teacher Education. Cham, Switzerland: Springer, 2018.

AHMED, S. The Cultural Politics of Emotion. New York, NY: Routledge, 2004.

ARAGÃO, R. C. Emoções no ensino/aprendizagem de línguas. In: ANDRADE, M. R. M. (org.). Afetividade e emoçoes no ensino/ aprendizagem de linguas: múltiplos olhares. São Paulo: Pontes Editores, 2011 p. 163-189.

BARCELOS, A. M. Desvelando a relação entre crenças sobre ensino e aprendizagem de línguas, emoções e identidades. In: GERHARDT, ; AMORIM, ; CARVALHO, A. M. (org.). Linguística Aplicada e ensino: língua e literatura. Campinas: Pontes, 2013. p. 153-186.

BARCELOS, A. M. Unveiling the Relationship Between Language Learning Beliefs, Emotions, and Identities. Studies in Second Language Learning and Teaching, [S.l.], v. 5, n. 2, p. 301-325, 2015. DOI: https://doi.org.10.14746/ssllt.2015.5.2.6

BARCELOS, A. M.; ARAGÃO, R. Emotions in Language Teaching: A Review of Studies on Teacher Emotions in Brazil. Chinese Journal of Applied Linguistics, Kyiv, UK, v. 41, n. 4, p. 506-531, 2018. DOI: https://doi.org/10.1515/cjal-2018-0036

BARCELOS, A. M. F.; RUOHOTIE-LYHTY, M. Teachers' Emotions and Beliefs in Second Language Teaching: Implications for Teacher Education. In: MARTÍNEZ AGUDO, J. de D. (ed.). Emotions in Second Language Teaching. Cham, Switzerland: Springer, 2018. p. 109-124. DOI: https://doi.org/10.1007/978-3319-75438-3_7

BARKHUIZEN, G. (ed.). Reflections on Language Teacher Identity Research. New York, NY: Routledge, 2017. DOI: https://doi.org/10.4324/9781315643465BENESCH, S. Considering Emotions in Critical English Language Teaching: Theories and Praxis. New York, NY: Routledge, 2012. DOI: https://doi.org/10.4324/9780203848135

BENESCH, S. Emotions and English Language Teaching: Exploring Teachers' Emotion Labor. New York; London: Routledge, 2017. DOI: https://doi. org/10.4324/9781315736181 
BENESCH, S. Exploring Emotions and Power in L2 Research: Sociopolitical Approaches. Modern Language Journal, Medford, MA, v. 103, n. 2, [s.p.], 2019. DOI: https://doi.org.10.1111/modl.12575

BOLER, M. Feeling Power: Emotions and Education. New York: Routledge. 1999. BOLER, M.; ZEMBYLAS, M. Discorforting Truths: The Emotional Terrain of Understanding Difference. In: TRIFONAS, P. (ed). Pedagogies of Difference: Rethinking Education for Social Justice. New York: Routledge-Falmer, 2003. p. 110-36.

BRASIL. Secretaria de Educação Básica. Orientações curriculares para o ensinomédio: linguagens, códigos e suas tecnologias - conhecimentos de línguas estrangeiras. Brasília: Ministério da Educação; Secretaria de Educação Básica, 2006. Disponível em: http://portal.mec.gov.br/seb/arquivos/pdf/book_volume_01_internet.pdf. Acesso em: 18 jun. 2020.

BRUNER, J. Acts of Meaning. Cambridge: Harvard University Press, 1990.

CLANDININ, D. J.; CONELLY, F. M. Pesquisa narrativa: experiências e história na pesquisa qualitativa. Tradução: Grupo de Pesquisa Narrativa e Educação de Professores ILEEL/UFU. Uberlândia: EDUFU, 2011.

COPE, B.; KALANTZIS, M. (ed.). Multiliteracies: Literacy Learning and the Design of Social Futures. London: Routledge, 2000.

CORBIN, J.; STRAUSS, A. Grounded Theory Research: Procedures, Canons, and Evaluative Criteria. Qualitative Sociology, [S.l.], v. 13, p. 3-21, 1990. DOI: https://doi. org/10.1007/BF00988593

DAY, C.; CHIN-KIN LEE, J. New Understandings of Teacher's Work: Emotions and Educational Change. New York, NY: Springer, 2011. DOI: https://doi. org/10.1007/978-94-007-0545-6

DENZIN, N. On Understanding of Emotion. San Francisco: Jossey-Bass, 1984.

DENZIN, N. On Understanding of Emotion. 2. ed. San Francisco: Jossey-Bass, 2007. DENZIN, N. Forward: Performance, Pedagogy and Emotionality. In: SCHUTZ, P. A.; ZEMBYLAS, M. (ed.). Advances in Teacher Emotion Research: The Impact on Teachers' Lives. New York, NY: Springer, 2009. p. v-vii.

DORNYEI, Z. Research Methods in Applied Linguistics. New York: Oxford University Press, 2007.

DUFF, P. How to Carry Out Case Study Research. In: MACKEY, A.; GASS, S. M. (ed.). Research Methods in Second Language Acquisition: A Practical Guide. New York: Wiley-Blackwell, 2012. p. 95-116. DOI: https://doi.org/10.1002/9781444347340. ch6 
FREIRE, Paulo. Pedagogia do oprimido. Rio de Janeiro: Paz e Terra, 2005.

GIROUX, H.A. Pedagogy and the Politics of Hope: Theory, Culture, and Schooling. Boulder, CO: Westview Press, 1997.

GOLEMAN, D. Inteligência emocional. 82. ed. Rio de Janeiro: Objetiva, 1995.

HARGREAVES, A. The Emotional Geographies of Teachers' Relations with Colleagues. International Journal of Educational Research, [S.l.], v. 35, n. 5, p. 503-527, 2001. DOI: 10.1016/S0883-0355(02)00006-X

HOCHSCHILD, A. R. Emotion Work, Feeling Rules and Social Structure. American Journal of Sociology, Chicago, v. 85, n. 3, p. 551-575, 1979. DOI: https://doi.org/10.1086/227049

HOCHSCHILD, A. R. The Managed Heart. Berkeley; London: University of California Press, 1983.

JUCÁ, L. C. V. Das histórias que nos habitam: por uma formação de professores de Língua Inglesa para o Brasil. 2017. 286f. Tese (Doutorado em Letras Estudos Linguísticos e Literários em Inglês) - Universidade de São Paulo, São Paulo, 2017.

KELCHTERMANS, G. Professional Commitment Beyond Contract. Teacher's Self Understanding, Vulnerability and Reflection. In: ZEMBYLAS, M.; SCHUTZ, P. A. (ed.). Methodological Advances in Research on Emotion and Education. Switzerland: Springer International Publishing, 2016. p. 31-42.

KUMARAVADIVELU, B. Beyond Methods: Macrostrategies for Language Teaching. Londres: Yale University Press, 2003.

KUMARAVADIVELU,B. Toward a Postmethod Pedagogy. TESOL Quarterly, [S.l.], v. 35, p. 537-557, 2001. DOI: http://dx.doi.org/10.2307/3588427

LANKSHEAR, C.; KNOBEL, N. New Literacies: Changing Knowledge and Classroom Learning. UK: Open University Press, 2003.

LUTZ, C. A. UnnaturalEmotions: Everyday Sentiments on a Micronesian Atoll and Their Challenge to Western Theory. Chicago: University of Chicago Press, 1988. DOI: https://doi.org/10.7208/chicago/9780226219783.001.0001

MATTOS, A. M. A. (org.). Narratives on Teaching and Teacher Education: an International Perspective. New York: Palgrave MacMillan, 2009. DOI: https://doi.org/10.1057/9780230622913 
MATTOS, A. M. A. O ensino de inglês como língua estrangeira na escola pública: novos letramentos, globalização e cidadania. 2011. 262f. Tese (Doutorado em Letras - Estudos Linguísticos e Literários em Inglês) - Universidade de São Paulo, São Paulo, 2011.

MATTOS, A. M. A. O ensino de inglês como língua estrangeira na escola pública: novos letramentos, globalização e cidadania. 2011. 262f. Tese (Doutorado) Programa de Pós-Graduação em Estudos Linguísticos e Literários, FFLCH/ USP, São Paulo, 2011.

MATTOS, A. M. A. Tornando-se um profissional crítico: Letramento Crítico como possibilidade para o fortalecimento de identidades e empoderamento de alunos e professores. In: SIMPÓSIO DE FORMAÇÃO E PROFISSÃO DOCENTE, 9., 2013. Atas [...]. Ouro Preto: UFOP, 2013.

MATTOS, A. M. A. Ensino de inglês como língua estrangeira na escola pública: letramento, globalização e cidadania. São Paulo: Paco Editorial, 2015.

MATTOS, A. M. A.; CAETANO, E. A. Os sentidos da formação: narrativas de professores de Inglês sobre suas experiências de ensino e aprendizagem. Revista do GELNE, Natal, v. 21, n. 1, p. 3-19, 2019. DOI: https://doi. org/10.21680/1517-7874.2018v20n2ID15824

MATTOS, A. M. A.; VALERIO, K. M. Letramento crítico e ensino comunicativo: lacunas e interseções. Revista Brasileira de Linguística Aplicada, Belo Horizonte, v. 10, n. 1, p. 135-158, 2010. DOI: https:/ /doi.org/10.1590/ S1984-63982010000100008

MENEZES DE SOUZA, L. M. T. Para uma redefinição de letramento crítico: conflito e produção de significação. In: MACIEL, R. F.; ARAÚJO, V. de A. (org.). Formação de professores de línguas: ampliando perspectivas. Jundiaí: Paco Editorial, 2011a. p. 128-140.

MENEZES DE SOUZA, L. M. T. O professor de inglês e os letramentos no século XXI: métodos ou ética? In: JORDÃO, C. M.; MARTINEZ, J. Z.; HALU, R. C. (org.). Formação "desformatada”: práticas com professores de língua inglesa. Campinas: Pontes Editores, 2011b. p. 279-303.

MONTE MÓR, W. Critical Literacies, Meaning Making and New Epistemological Perspectives. Revista Electrónica Matices en Lenguas Extranjeras, Bogotá, n. 2, p. 1-18, 2008. 
MONTE MÓR, W. Crítica e letramentos críticos: reflexões preliminares. In: ROCHA, C. H.; MACIEL, R. F. (org.). Lingua estrangeira e formação cidadã por entre discursos e práticas. Campinas: Pontes Editores, 2013. p. 31-50.

NIAS, J. Thinking About Feeling: The Emotions in Teaching. Journal of Education, Cambridge, v. 26, p. 293-306, 1996. DOI: https://doi. org/10.1080/0305764960260301

PAVLENKO, A. The Affective Turn in SLA: From 'Affective Factors' to 'Language Desire' and 'Commodification of Affect.' In: GABRYŚ-BARKER, D.; BIELSKA, J. (ed.). The Affective Dimension in Second Language Acquisition. Bristol, UK: Multilingual Matters, 2013. p. 3-28.

PENNYCOOK, A. Introduction: Critical Approaches to TESOL. TESOL Quarterly, [S.l.], v. 33, n. 3, p. 329-348, 1999. DOI: https://doi.org/10.2307/3587668 RAJAGOPALAN, Kanavillil. Por uma lingüistica crítica: linguagem, identidade e questão ética. São Paulo: Parábola Editorial, 2003. p.144.

SCHUTZ, P. A.; ZEMBYLAS, M. Introduction to Advances in Teacher Emotion Research: The Impact on Teachers' Lives. In: (ed.). Advances in Teacher Emotion Research: The Impact on Teachers' Lives. New York: Springer, 2009. p. 3-11. DOI: https://doi.org/10.1007/978-1-4419-0564-2_1

TRACY, S. J.; TRETHEWEY, A. 'Fracturing the Real-Self $\leftrightarrow$ Fake-Self Dichotomy: Moving Toward Crystallized Organizational Identities'. Communication Theory, Oxford, v. 15, n. 2, p. 168-95, 2005.

ZEMBYLAS, M. Emotions and Teacher Identity: A Poststructural Perspective. Teachers and Teaching, [S.l.], v. 9, n. 3, p. 213-238, 2003. DOI: https://doi. org.10.1080/13540600309378

ZEMBYLAS, M. Teaching with Emotion: A Postmodern Enactment. Greenwich, CT: 2005.

ZEMBYLAS, M. The Power and Politics of Emotions in Teaching. In: SCHUTZ, P. A.; PECKRUN, R. (ed.). Emotions in Education. New York: Academic Press. 2007. p. 293-309. DOI: https://doi.org/10.1016/B978-012372545-5/50018-6

ZEMBYLAS, M.; CHUBBUCK, S. M. Teachers' Emotions in Times of Change in Europe: Exploring Teachers' Emotional Experiences and Social Justice Education. In: LISTON, D.; DAY, C. (ed.). International Handbook on Teacher and School Development. New York: Routledge, 2009.

Data de submissão: 29/06/2020. Data de aprovação: 26/10/2020. 